\title{
Aplicación de técnicas de cultivo in vitro en la propagación de Legrandia concinna*
}

\author{
Application of in vitro cultivation techniques in the propagation of Legrandia concinna \\ MATILDE URIBE-MORAGA, LUIS CIFUENTES G. \\ Departamento de Ciencias Básicas, Unidad Académica Los Angeles, Universidad de Concepción, \\ Casilla 341, Los Angeles, Chile. E-mail: muribe@udec.cl
}

\begin{abstract}
SUMMARY
Legrandia concinna (Phil.) Kausel is a native tree under protection and classified as vulnerable. It is a small tree with very hard wood that is used for making tool handles. However, although no other specific uses are known, it is a species with a high ornamental potential. There is a substantial lack of knowledge about this species, in particular about propagation methods such as tissue culture or micropropagation. Nowadays, in vitro culture has proven to be an excellent way to increase the number of individuals of woody species, especially those that are being conserved. Luma del Norte (Legrandia concinna) was established in vitro by using internodal segments with axillary shoots of juvenile plants (three years old). The establishment response and the organogenic multiplication of the explants in two media, MS and DWK, and two hormonal combinations, $0.1 / 1 \mathrm{mg} / \mathrm{l}$ and $0.1 / 0.5 \mathrm{mg} / \mathrm{l} \mathrm{of}$ IBA and BAP, respectively, were evaluated by experimental factorial analysis. The best results were obtained with MS media and a hormonal combination of $0.1 / 0.5 \mathrm{mg} / \mathrm{l}$ of AIB and BAP, respectively.
\end{abstract}

Key words: axillary shoot, internodal segment, IBA: Indole butyric acid, BAP: Belzylaminopurine.

\section{RESUMEN}

Legrandia concinna (Phil.) Kausel es un árbol nativo que se encuentra en estado de conservación bajo la categoría de Vulnerable. Es un árbol pequeño que no alcanza grandes dimensiones; se caracteriza porque su madera es muy dura, utilizándose en la fabricación de mangos de herramientas; no se conocen otros usos específicos; sin embargo, es una especie que posee un alto potencial ornamental. Existe un gran desconocimiento de la especie y en particular sobre sus sistemas de propagación. Estos últimos han sido investigados en relativa profundidad y no existe información acerca de los métodos de propagación mediante cultivo de tejidos o micropropagación. Actualmente el cultivo in vitro se ha constituido en una vía excelente para incrementar el número de individuos de especies leñosas, especialmente las que se encuentran bajo estado de conservación. Se estableció in vitro Luma del Norte, utilizando segmentos nodales con yemas axilares de plantas juveniles (tres años). A través de un experimento factorial se evaluaron las respuestas de establecimiento y multiplicación organogénica de los explantes en dos medios basales: MS y DKW y dos combinaciones hormonales $0,1 / 1$ y $0,1 / 0,5 \mathrm{mg} / \mathrm{l}$ de AIB y BAP respectivamente. Los mejores resultados se obtienen con medio MS y combinación hormonal 0,1/0,5 mg/l de AIB y BAP respectivamente.

Palabras claves: yemas axilares, segmentos nodales, AIB: ácido indolbutírico, BAP: bencilaminopurina.

\section{INTRODUCCION}

Legrandia concinna (Phil.) Kausel, conocida vulgarmente como Luma del Norte, es una espe- cie perteneciente a la familia Myrtaceae, endémica de Chile y en estado de conservación bajo la categoría de Vulnerable por el primer simposio sobre Flora Arbórea y Arbustiva Nativa de Chile (1).

* Estudio financiado por la Universidad de Concepción, Proyecto DIUC No 200.412.002-1.0 (200-2002). 
BOSQUE 25(1): 129-135, 2004

Aplicación de técnicas de cultivo in vitro en la propagación de Legrandia concinna

Es una especie higrófila que crece en quebradas húmedas o cerca de cursos de agua, formando asociaciones más o menos puras, de poca extensión y acompañada, por lo general, de algunos ejemplares esparcidos de Nothofagus obliqua. Actualmente, se le puede encontrar en un área muy restringida ubicada desde el Sur de la provincia de Linares (VII Región) hasta el Norte de la provincia de Ñuble (VIII Región), en la precordillera andina y hasta 1.000 ms.n.m. aproximadamente (2). En todas las poblaciones conocidas se observa un reducido número de individuos ubicados en su mayoría en zonas de alteración ambiental. El reducido contingente de las poblaciones, su restringida área de distribución geográfica y la fuerte presión antrópica por su entorno, ameritarían su traspaso de especie Vulnerable a En Peligro (3).

Luma del Norte es un árbol pequeño que alcanza dimensiones de entre 2 a $5 \mathrm{~m}$ de altura; no obstante, puede llegar hasta los $10 \mathrm{~m}$ de altura y posee un tronco con dimensiones de hasta $40 \mathrm{~cm}$ de diámetro. Florece de diciembre a enero y sus flores son de color blanco. Su fruto es una baya redondeada de 1,5 a $2,0 \mathrm{~cm}$, amarilla o rojiza a negro-violácea en la madurez; el fruto madura entre marzo y abril, conteniendo de 1 a 3 semillas redondeadas café oscuras (4).

Esta especie se caracteriza porque su madera es muy dura y resistente, utilizándose en la fabricación de mangos de herramientas y en algunos elementos rústicos de labranza. No se conocen otros usos específicos; sin embargo, es una especie que presenta un alto potencial ornamental, ya que cuenta con características que le permiten desarrollarse como tal, posee hoja perenne, un fruto muy atractivo, no alcanza grandes dimensiones, es de crecimiento lento y muy aromática, por lo que se recomienda para plazas, parques y jardines (4).

La producción de Luma del Norte en vivero se presenta normalmente sin grandes dificultades, requiriendo de algunas condiciones simples para su buen desarrollo, tales como semisombra, un suelo húmedo y un riego mediano. Sin embargo, normalmente en especie bajo estado de conservación se enfrenta el problema de disponibilidad de material para desarrollar su propagación por técnicas tradicionales. En este contexto la distribución natural de muchas especies nativas $y$, en particular, Luma del Norte, ha sufrido un gran deterioro debido a la explotación irracional que sufrieron en el pasado a través de la extracción indiscriminada de los mejores individuos y a causa de la sustitución por plantaciones forestales, razón por la cual actualmente encontramos un reducido número de individuos. Asumiendo que estas últimas van en un aumento progresivo, no es seguro que el establecimiento de leyes de protección de la Flora Nativa (1) garantice la sobrevivencia de esta especie (5).

No obstante, a través de métodos de propagación tradicional aún existen limitaciones y dificultades importantes, tales como lentitud en el proceso de germinación, irregularidad en la obtención de plántulas para formar una población homogénea, en cuanto edad y tamaño, obtención de semillas a intervalos irregulares y con escasa viabilidad, etc. (5-9). Por tanto, el cultivo in vitro o micropropagación se presenta como una excelente alternativa para superar las dificultades antes mencionadas de los métodos tradicionales en la producción de una amplia gama de especies (7), ya que por medio de esta técnica es posible reproducir clones con alto valor genético $\mathrm{y}$, además, conseguir plantas de alta calidad que pueden llegar incluso a triplicar las ganancias económicas (10).

En este trabajo se propone una alternativa metodológica de propagación, desarrollando un protocolo de establecimiento y multiplicación organogénica por medio de la técnica del cultivo in vitro, que permitirá regenerar individuos de Luma del Norte, con fines futuros de recuperación, conservación y reforestación de la especie.

\section{MATERIAL Y METODOS}

El estudio consiste en evaluar en una primera etapa la tasa de supervivencia de Luma del Norte bajo cultivo in vitro (etapa de establecimiento) y en segundo lugar determinar el medio de cultivo más adecuado para el desarrollo de la especie y el tipo de combinación hormonal más efectivo en el proceso de multiplicación in vitro (etapa de proliferación).

Material vegetal y condiciones de cultivo. El material utilizado como fuente inicial de explantes 
corresponde a plántulas obtenidas a partir de semillas germinadas y mantenidas durante tres años en vivero de propiedad de Forestal y Agrícola Monte Aguila (Los Angeles). A partir de estas plántulas se escindieron ramas laterales, a las cuales se les eliminaron las hojas a nivel del pecíolo. Posteriormente en la sala de lavado se procedió a limpiar el material vegetal bajo agua corriente durante 5 minutos. Transcurrido este período se transfirieron a un recipiente plástico conteniendo una solución fungicida (Captan 2,5 g/l), luego de 3 minutos de inmersión en esta solución se realizó un enjuague del material en agua destilada estéril durante 2 minutos, para finalmente extraer los explantes (segmentos nodales) e iniciar la asepsia posterior.

La esterilización superficial de los explantes se realizó en condiciones asépticas, bajo cámara de flujo laminar y en agitación continua, por medio de inmersión en alcohol al 70\% (v/v) durante 30 segundos. Posteriormente se realizó un lavado en agua destilada estéril por 2 minutos e inmersión en una solución de cloro comercial al $50 \%$ (v/v) más Tween 20 durante 15 minutos. Finalmente, se efectuaron 4 lavados consecutivos en agua destilada estéril durante 2, 5, 15 y 20 minutos respectivamente y los explantes fueron secados por contacto con papel filtro estéril, para su posterior incubación in vitro.

Se seleccionaron dos medios bases para el cultivo de especies leñosas MS (11) y DKW (12). A ambos medios se les adicionaron $30 \mathrm{~g} / \mathrm{l}$ de sacarosa y $0,8 \%$ de agar bacteriológico como agente gelificante. Una vez preparada la solución de cultivo el pH de los medios se ajustó a 5,8 con $\mathrm{NaOH}$ $0,1 \mathrm{~N}$ y se esterilizó en autoclave durante $20 \mathrm{mi}-$ nutos a 1 atmósfera de presión y $121^{\circ} \mathrm{C}$ de temperatura. Los explantes fueron cultivados en cámara de crecimiento bajo condiciones controladas a $25 \pm 2^{\circ} \mathrm{C}$ de temperatura, $55 \%$ de humedad relativa, bajo un fotoperíodo de 16 horas de luz fría y a una intensidad lumínica de 2.000 lux.

Etapa de establecimiento. Durante esta fase del ensayo se incubaron 128 explantes para el medio MS y 120 para el medio DKW. Los explantes, dos por recipiente, se dispusieron en posición vertical y los cultivos fueron sellados con papel aluminio y parafilm; se incubaron en cámara de crecimiento en las condiciones indicadas previamente. Tras 45 días de cultivo, se procedió a evaluar el porcentaje de explantes viables y el tipo de contaminación.

Iniciación y proliferación caulinar. A partir de los microtallos más vigorosos obtenidos después de 45 días en medio MS y DKW, durante la etapa de establecimiento se cortaron brotes individuales, de tal manera de homogenizar en lo posible la longitud de ellos (10-15 mm), para dar origen a los explantes primarios. Estos se obtienen también, seleccionando todos aquellos que presentan un adecuado estado sanitario y eliminando aquellos que presentan algún grado de infección.

Posteriormente son cultivados en medio de proliferación para el establecimiento de cadenas cicloclonales. La inducción de respuestas proliferativas se efectuó en los medios antes mencionados, suplementados con dos combinaciones de citoquininas (BAP 0,5 y 1,0 mg/l), manteniendo constante la concentración de auxina (AIB 0,1 mg/ 1). Tras 45 días de cultivo en los medios nutritivos los explantes se transfirieron a medio MS y DKW basal, cuantificándose las respuestas proliferativas al término de 90 días. En esta etapa se analizaron los efectos individuales o interacciones producidas por la acción de los medios de cultivo y las fitohormonas sobre el crecimiento y desarrollo de los microtallos y que son estadísticamente apreciables. Para tal efecto, se evaluaron 3 variables: número de brotes por explantes, longitud de los brotes y número de hojas por brote.

Diseño experimental. El análisis estadístico del experimento se realizó mediante un diseño completamente aleatorio. Los resultados de las variables analizadas fueron sometidos a un análisis de varianza (ANDEVA) factorial (2X2) (13). La unidad experimental para cada una de las variables estuvo conformada por grupos de cuatro explantes, con 6 repeticiones para el tratamiento uno, 4 repeticiones para el tratamiento dos y 5 repeticiones para los tratamientos tres y cuatro. Para el análisis de cada una de las variables, los datos promedios de las unidades muestrales se evaluaron mediante un programa estadístico con un nivel de significación de 0,05 y verificando la homogeneidad de varianza con el test de Levene's. Los tratamientos evaluados fueron (cuadro 1): 
BOSQUE 25(1): 129-135, 2004

Aplicación de técnicas de cultivo in vitro en la propagación de Legrandia concinna

\section{CUADRO 1}

Tratamientos evaluados para la regeneración de microtallos de Luma del Norte a partir de segmentos nodales.

Treatments evaluated for the regeneration of stems in Luma del Norte starting from internodal segments.

\begin{tabular}{|c|c|c|c|}
\hline $\begin{array}{c}\text { Trata- } \\
\text { mientos }\end{array}$ & $\begin{array}{c}\text { Medio de } \\
\text { cultivo }\end{array}$ & $\begin{array}{c}\text { BAP } \\
(\mathrm{mg} / \mathrm{l})\end{array}$ & $\begin{array}{c}\text { AIB } \\
(\mathrm{mg} / \mathrm{l})\end{array}$ \\
\hline $\mathrm{T} 1$ & MS & 1,0 & 0,1 \\
$\mathrm{~T} 2$ & $\mathrm{MS}$ & 0,5 & 0,1 \\
$\mathrm{~T} 3$ & DKW & 1,0 & 0,1 \\
$\mathrm{~T} 4$ & DKW & 0,5 & 0,1 \\
\hline
\end{tabular}

\section{RESULTADOS Y DISCUSION}

Etapa de establecimiento. Los resultados de supervivencia fueron similares, tanto para el medio de cultivo MS como para DKW (figura 1). La alta tasa de mortalidad obtenida se asocia a la actividad de agentes de tipo fúngico y bacteriano que se encuentran alojados en los tejidos internos del material vegetal. Según Pierik (6), el material vegetal, a pesar de ser esterilizado antes del aislamiento, no siempre es completamente estéril y sólo se hace visible cuando el centro infeccioso es escindido (durante el repicado) y se pone en contacto con el medio de cultivo. Sin embargo, la selección de explantes primarios al final de la etapa de establecimiento permitió que la etapa de proliferación fuera todo un éxito, ya que se eliminó un alto grado de infección.

\section{ETAPA DE PROLIFERACION}

a) Número de brotes. Según Hartmann y Kester (7), la función de la etapa de multiplicación in vitro es incrementar el número de propágulos en cultivo. Es así como los resultados derivados de este estudio, a partir de segmentos nodales nos permite observar el desarrollo de yemas axilares que darán origen a nuevos brotes (figura 2).

Respectivamente, los resultados del análisis ANDEVA para las variables factor medio de cultivo y factor hormonal no permitieron evidenciar diferencias significativas entre los dos medios de proliferación y las combinaciones hormonales estudiadas. A pesar de que no existen diferencias, la

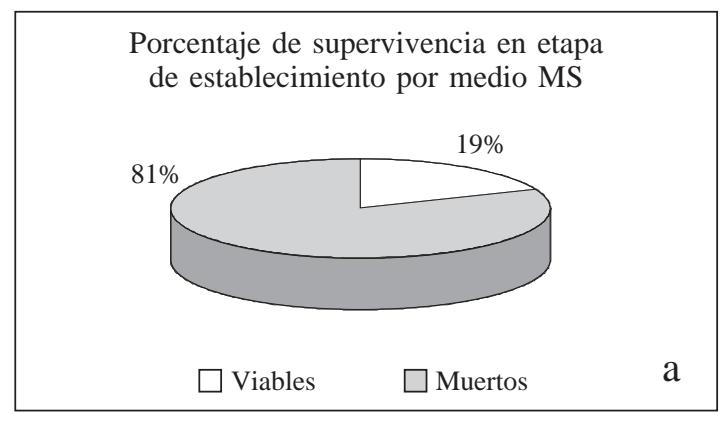

Porcentaje de supervivencia en etapa de establecimiento por medio DKW

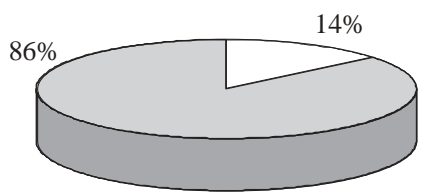

$\square$ Viables

$\square$ Muertos

b

Figura 1. Porcentaje de supervivencia: a) medio MS; b) medio DKW.

Percentage of survival in: a) MS media; b) DKW media.

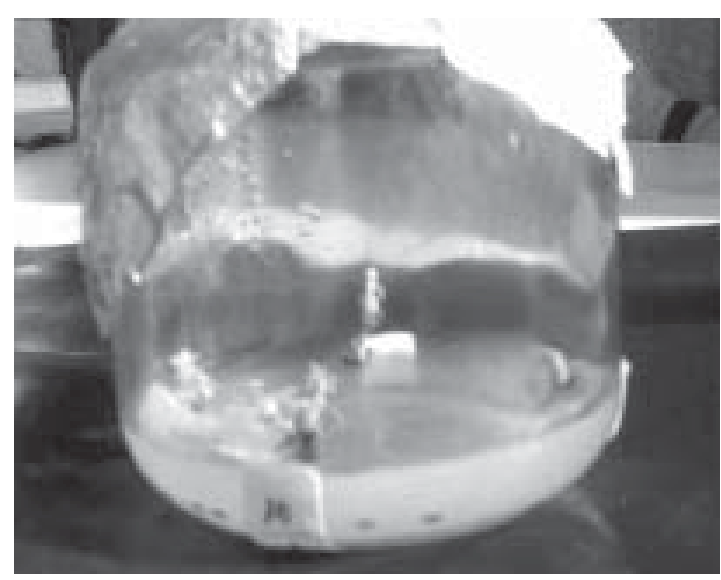

Figura 2. Incremento en el número de brotes durante la etapa de proliferación bajo tratamiento 2 , tras 45 días de cultivo.

Increase in the number of buds during the proliferation phase of treatment 2 , after 45 days of culture.

figura 3 muestra una marcada tendencia con mejores resultados para el medio MS, probablemente por la mayor concentración de algunos elementos, como, por ejemplo, el nitrógeno y el potasio, que tienen una acción estimulante sobre la formación de yemas (14). Sin embargo, López (15) señala que en muchas especies el desarrollo de yemas se 
ve favorecido usando medios nutritivos reducidos en concentración de sales, pero es importante señalar que el efecto de las sales minerales depende exclusivamente de la especie utilizada(6).

Por otra parte, Barceló et al. (16) señalan que, al aplicar hormonas (auxina/citoquinina) al medio de cultivo, debe existir un balance entre ambos; así, al aumentar la cantidad de citoquinina con respecto a la auxina, se induce la formación de brotes. Pierik (6), por su lado, señala que las necesidades de citoquinina (tipo de citoquininas y concentración) son extremadamente variables y dependen del contenido endógeno de cada especie.

En este sentido, de la figura 3 se desprende que el desarrollo de brotes se ve favorecido mayormente por el tratamiento 2 (MS 0,1/0,5 mg/l AIB/BAP), siendo menos eficientes los otros tratamientos para la formación de brotes, obteniéndose en promedio 12,7 brotes/unidad experimental. Estos resultados coinciden con los obtenidos por Muñoz (17), quien señala que un aumento en la concentración hormonal origina la proliferación de una gran cantidad de brotes. Según Vieitez y Vieitez (18), a concentraciones de 1 ó $2 \mathrm{mg} / \mathrm{l}$ de BAP se obtiene el máximo número de brotes en material juvenil, faltando elongación de éstos y ocasionando arrosetamiento de los explantes, por lo que concluyeron que la concentración óptima para la proliferación se encuentra entre $0,1-0,5 \mathrm{mg} / \mathrm{l}$ y que la multiplicación de brotes en medio carente de BAP es prácticamente nula (19).

b) Longitud de brotes. Otra de las respuestas de interés obtenidas a partir del cultivo in vitro, que se asocia con el crecimiento y desarrollo, es la elongación de los microtallos, parámetro que se ve fuertemente afectado por el tiempo de exposición en cultivo.

Con respecto al factor medio de cultivo, el análisis estadístico no entregó diferencias significativas entre los medios de proliferación. No obstante, en relación con el factor hormonal, el ANDEVA fue bastante más categórico, ya que se registró una diferencia significativa entre los dos tipos de combinaciones hormonales, obteniéndose mejores resultados y siendo más efectiva la combinación $0,1 / 0,5 \mathrm{mg} / \mathrm{l}$ (figura 4 ). Los brotes tratados con este método combinado logran incrementos de al menos $2 \mathrm{~cm}$ (figura 5).

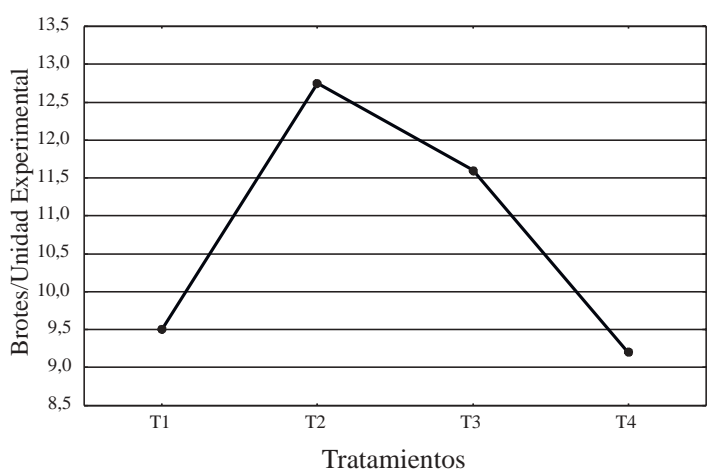

Figura 3. Efecto del tipo de tratamiento en el número de brotes obtenidos.

Effect of the type of treatment on the number of shoots obtained.

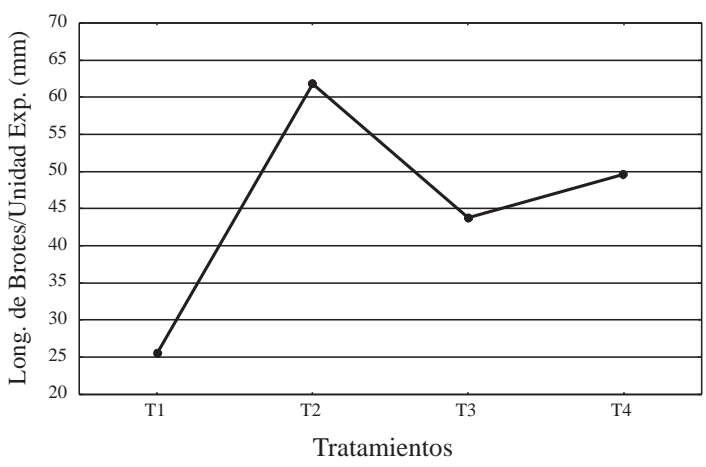

Figura 4. Altura de los microtallos en la etapa de proliferación-manifestación para los diferentes tratamientos.

Height of stems in the manifested-proliferation stage for the different treatments.

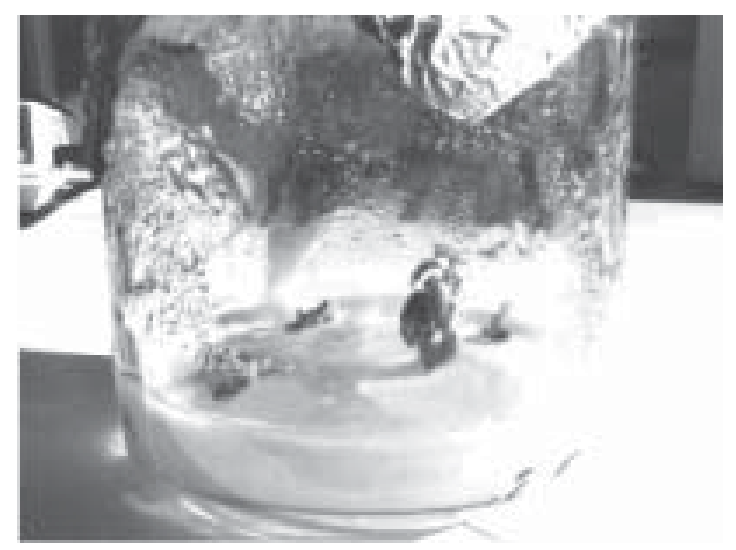

Figura 5. Incremento en la longitud de brotes en medio basal MS tras 45 días de cultivo en medio de proliferación.

Increase in bud length in the basal media MS after 45 days in proliferation media. 
BOSQUE 25(1): 129-135, 2004

Aplicación de técnicas de cultivo in vitro en la propagación de Legrandia concinna

Al respecto, Arredondo (20) señala que, para obtener microtallos de mayor longitud, es necesario que el medio de cultivo sea suplementado con una menor concentración de citoquininas, ya que con esto se logra disminuir la división celular y favorecer la elongación del tejido por la acción de las auxinas. Esto confirma lo descrito por Kyte y Kleyn (21), en cuanto a que una mayor concentración de citoquininas induce la formación de brotes más pequeños. Además, los resultados corroboran lo señalado por Calderón-Baltierra y Rotella (22), quienes determinaron que con una baja concentración de citoquininas, o en ausencia de éstas, se consigue una mayor elongación.

La obtención de microtallos más largos se debe fundamentalmente a la utilización de explantes apicales, es decir, que cuentan con la presencia de la yema apical, que posibilita el crecimiento en esa dirección regulado por las fitohormonas (9). En los explantes que no cuentan con yema apical (segmentos medios y basales), la respuesta a la acción de los reguladores de crecimiento adicionados al medio de cultivo es tardía y se relaciona al desarrollo y activación de yemas axilares en estado de parcial o total inhibición (7).

c) Número de hojas. Durante la etapa de proliferación se observa un incremento paulatino de las respuestas a medida que aumenta el tiempo de cultivo, entre las cuales se destaca la aparición de hojas (figura 6).

En relación con el factor medio de cultivo, al igual que para los casos anteriores, el análisis ANDEVA no indicó diferencias significativas entre los medios de proliferación, Sin embargo, la

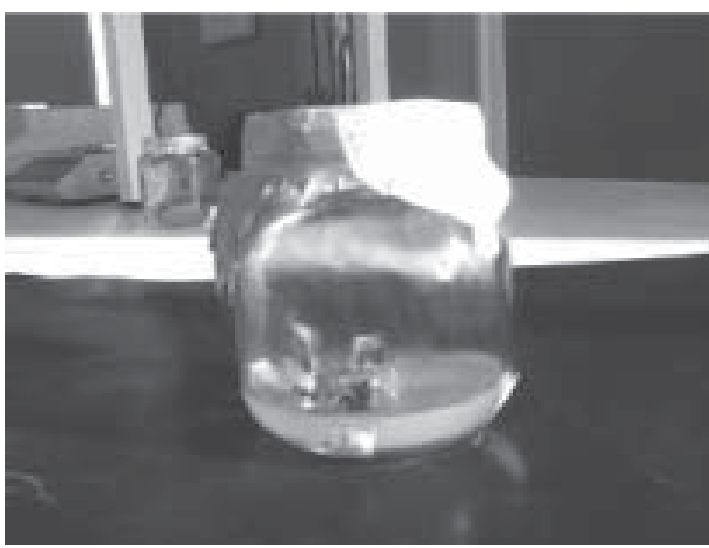

Figura 6. Incremento en el número de hojas por brotes en medio de proliferación.

Increase in the number of leaves per bud in the proliferation media. figura 7 muestra una mejor respuesta en el medio MS (80 hojas/unidad experimental).

Con respecto al factor hormonal, el análisis fue bastante más categórico, ya que señala que sí existen diferencias estadísticamente significativas entre los dos tipos de combinaciones hormonales, obteniéndose mejores resultados y siendo más efectiva la combinación 0,1/0,5 mg/l (figura 7).

Según Calderón et al. (23), a medida que aumentan los días de cultivo aumenta la aparición de hojas. Igualmente, en estudios realizados en avellano chileno, Mardones (5) concluyó que el número de verticilos se incrementa a medida que se aumenta el tiempo de permanencia de los microtallos en la cámara de cultivo. Burch y McGaw (24) señalan que el incremento endógeno en citoquininas produce cambios en el desarrollo de la senescencia de las hojas o el incremento del crecimiento del brote.

De la figura 7 se desprende que el desarrollo de hojas alcanza su valor más alto en el tratamiento 2 , siendo poco efectivos los otros tratamientos. La baja cantidad de verticilos generados se puede atribuir a la baja síntesis de citoquininas, cuya explicación radicaría en el incremento de la longitud presentada por los microtallos, indicando la existencia de una alta síntesis de auxinas en los tejidos y no de citoquininas o porque los niveles endógenos de auxinas se encuentran por sobre los de citoquininas (5)

\section{CONCLUSIONES}

El protocolo desarrollado en este estudio permite propagar Legrandia concinna a través del cultivo in vitro mediante segmentos nodales con

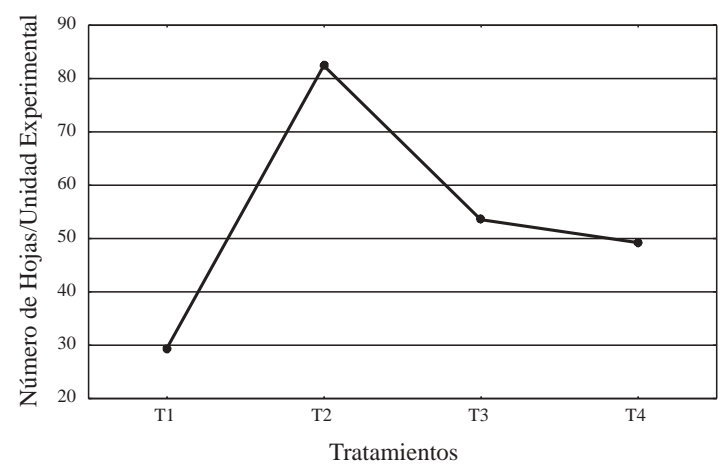

Figura 7. Número de hojas/unidad experimental para los 4 tratamientos empleados.

Number of leaves/experimental units for the four treatments employed. 
yemas axilares, ofreciendo una vía adecuada para multiplicar y preservar esta especie en vías de extinción a través de la metodología propuesta en este trabajo.

El principal problema en la etapa de establecimiento fue la contaminación fúngica, dando paso, posteriormente, a una predominancia de contaminación por bacteria, concluyéndose que las condiciones de pretratamiento de la planta madre son un elemento de suma importancia para el éxito del cultivo. Los mejores resultados de respuesta organogénica de los segmentos nodales cultivados in vitro se obtuvieron en medio de cultivo MS y la combinación hormonal $0,1 / 0,5 \mathrm{mg} / \mathrm{l}$ de AIB/BAP, respectivamente. El siguiente paso es su establecimiento en condiciones ex vitro, investigación que se está llevando a cabo actualmente por medio de ensayos de enraizamiento in vitro.

\section{AGRADECIMIENTOS}

Los autores agradecen al Dr. Carlos LeQuesne (CONAF, Universidad Austral de Chile) y a Forestal y Agrícola Monte Aguila (Los Angeles) por proveer el material vegetal utilizado en este estudio. A la Dra. Darcy Ríos L. (Facultad de Ciencias Forestales, Universidad de Concepción) por su incondicional apoyo científico a lo largo de nuestra investigación. Al MSc. Víctor Jara S. (Unidad Académica Los Angeles, Universidad de Concepción), por su colaboración en el análisis estadístico de los resultados.

\section{BIBLIOGRAFIA}

(1) BENOIT, I. Libro Rojo de la Flora Terrestre de Chile. Ministerio de Agricultura. Santiago Chile. (CONAF). 1989. $157 \mathrm{p}$.

(2) RODRIGUEZ, R., O. MATTHEI, M. QUEZADA. Flora arbórea de Chile. Concepción: Ed. Universidad de Concepción. 1983. 407 p.

(3) CONAF. Actas Simposio Flora Nativa Arbórea y Arbustiva de Chile amenazada de extinción. Santiago: Ministerio de Agricultura. 1985. 80 p.

(4) RODRIGUEZ, G., R. RODRIGUEZ, H. BARRALES. Plantas ornamentales chilenas. Concepción: Gráfica Lamas. 1995.30 p.

(5) MARDONES, L. Recuperación de genotipos de avellano chileno (Gevuina avellana Mol.), mediante cultivo in vitro de embriones. Memoria de Título. Universidad de Con- cepción, Facultad de Ciencias Forestales, Concepción, Chile. $1999.40 \mathrm{p}$.

(6) PIERIK, R. Cultivo in vitro de plantas superiores. Madrid: Ediciones Mundi-Prensa. 1990. 301 p.

(7) HARTMANN, H., D. KESTER. Propagación de plantas: Principios y prácticas. $7^{\mathrm{a}}$ ed. México D.F.: Compañía Editorial Continental S.A. 1999. 760 p.

(8) SABJA A. M. Micropropagación de Eucalyptus globulus: Los bosques del futuro. Chile Forestal (Chile), 1999, $\mathrm{N}^{\circ} 257$, p. $9-12$.

(9) URIBE, M. Poliaminas y manipulación de la morfogénesis en el género Pinus L. Tesis doctoral. Universidad de Oviedo, España. 2000. 178 p.

(10) LAGOS, E. Castaño: especie con doble propósito. Chile Forestal (Chile), 1997, No 252, p. 14-16.

(11) MURASHIGE T., F. SKOOG. A revised medium for rapid growth and bioassays with tobacco tissue cultures. Physiol. Plant., 1962, Vol. 15, p. 473-497.

(12) DRIVER D., A. KUNIYUKI. In vitro propagation of Paradox walnut rootstock. Hortscience, 1984, Vol. 19, p. 507-509.

(13) CANAVOS, G. Probabilidad y Estadística. Aplicaciones y Métodos. Madrid: McGraw-Hill. 1992. 651 p.

(14) MARGARA, J. Multiplicación vegetativa y cultivo in vitro. Los meristemos y la organogénesis. Madrid: Ediciones Mundi-Prensa. 1988. 232 p.

(15) LOPEZ, M. Regeneración de plántulas a partir de cotiledones aislados de Pinus nigra Arn. subesp. Salzmann (Dunal) Franco. 1998, Cap. II: 21-42 p. Tesis doctoral. Universidad de Oviedo, España.

(16) BARCELO, J, G, NICOLAS, B, SABATER, R, SAN CHEZ. Fisiología Vegetal. $6^{\mathrm{a}}$ ed. Madrid: Ediciones Pirámide S.A. 1995. 662 p.

(17) MUÑOZ M. Multiplicación in vitro de clones selectos de Castanea sativa Mill. Memoria de Título. Universidad de Concepción, Facultad de Ciencias Forestales, Concepción, Chile. 2000. 39 p.

(18) VIETEZ A. M., E. VIETEZ. Plantlet formation from embryonic tissue of chestnut grown in vitro. Physiol. Plant. 1980, Vol. 50, p. 127-130.

(19) VIETEZ A., M. VIETEZ. Castanea sativa plantlets proliferated from axillary buds cultivated in vitro. Sciencia Horticulturae, 1982, Vol. 18, p. 343-351.

(20) ARREDONDO, A. Establecimiento de cadenas proliferativas y enraizamiento in vitro de Juglans regia L. a partir de embriones. Memoria de Título. Universidad de Concepción, Facultad de Ciencias Forestales, Concepción, Chile. 2000. 55 p.

(21) KYTE, L., J. KLEYN. Plants from test tubes: an introduction to micropropagation. $3^{\mathrm{a}}$ ed. U.S.A. Portland: Timber Press. 1996. 240 p.

(22) CALDERON-BALTIERRA X., A. ROTELLA. Establecimiento in vitro de Beilschmiedia berteroana (Gay) Kostermans (Lauraceae). Información Tecnológica, 1998 Vol. 9, $\mathrm{N}^{\circ} 5$, p. 269-275.

(23) CALDERON-BALTIERRA X., F. PEREZ, A. ROTELLA Micropropagación de una especie chilena en peligro de extinción: Gomortega keule (Mol.) Baillon (Magnoliopsidae, Gomortegaceae). Bosque (Chile), 1993, Vol. 14, $\mathrm{N}^{\mathrm{o}} 1$, p. $23-28$.

(24) BURCH, L., B. MCGAW. Fisiología y Bioquímica Vegetal. In: AZCON-BIETO, J., M. TALON. Madrid, España: McGraw-Hill., 1993, p. 319-325. 